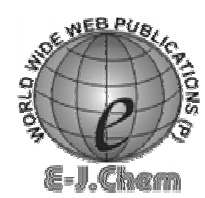

http://www.e-journal.net

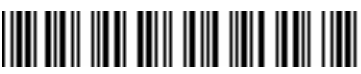

ISSN: 0973-4945; CODEN ECJHAO

E-Journal of Chemistry

Vol. 1, No. 2, pp 137-141, April 2004

\title{
Inhibition of Mineralization of Urinary Stone Forming Minerals by Hills Area Fruit
}

\author{
N. A. MOHAMED FAROOK*, G. A. SEYED DAMEEM, N. M. I. ALHAJI, \\ R. SATHIYA, J. MUNIYANDI, S. SANGEETHA and J. MUNIYANDI. \\ P. G \& Research Department of Biochemistry, \\ Khadir Mohideen College, \\ Adirampattinam - 614 701, India. \\ nafarook@hotmail.com
}

Received 15 March 2004; Accepted 30 March 2004

\begin{abstract}
Some hills area fruit, viz., star fruit, butter fruit, seetha fruit, and watermelon have been investigated as inhibitors in the mineralization of urinary stone forming minerals, viz., calcium phosphate, oxalate and carbonate. Inhibition efficiency has been studied in different models. Increased intake of the experimental fruits would be helpful in urinary stone proppylaxis. Most of the inhibitors have found effectively inhibit calcium phosphate and oxalate precipitation..
\end{abstract}

Keywords: Inhibition, Urinary stone, Hills area fruits, In-vitro study

\section{Introduction}

Calcium is the most abundant metal found in the body. It constitutes about $2 \%$ of the total body weight. Renal calcui consists of mucopolysaccharides, urates, calcium oxalate, calcium phosphate and calcium carbonate. ${ }^{1,2}$ Urate and oxalate stones are the most common. Cysteine stone are rare. Several factors contribute to the formation of stones, viz., climate, occupation, infection of the urinary tract, dietary habits-habitual intakes of foods rich in oxalates, calcium, phosphate and purines and hereditary. Calcium is taken in diet as calcium phosphate, carbonate, tartarate and oxalate. Approximately, only $30 \%$ of the dietary calcium is absorbed actively from the small intestine, more readily in the upper than in the lower portion. The absorption of calcium is effected by a number of factors.

Epidemiological studies ${ }^{3-6}$ indicate that urolithiasis disease exists in 'endemic' proportions in some parts of our country. Urinary stones contain both crystalloid and colloid components. Stone formation is apparently related to the level of urinary crystalloid and also to the level of inhibitors of calculogenesis in urine, ${ }^{7-9}$ Quest for physiologically non-toxicant natural inhibitors of urolithiasis would be helpful in the prevention of this disease. 
The present study has been suitably designed so as to investigate the inhibition efficiency of fruit juice viz, star fruit, butter fruit, seetha fruit, and watermelon on the mineralization of calcium oxalate, calcium carbonate and calcium phosphate, in different models. ${ }^{10}$

\section{Experimental}

\section{Preparation of reagents and solution}

All the chemicals used were of AR grade. Crystalloid forming solutions, viz., solution of calcium acetate, disodium oxalate, sodium carbonate and trisodium phosphate, were prepared in distilled water.

Juice of the fruits was extracted with help of an ordinary fruit juicer. The thick juice obtained, were passed through a mesh and then suction filtered through ordinary filter paper. All the juices were used diluted to a known concentration.

Four experimental models namely 'simultaneous flow static model' (S.S.M.), 'simultaneous flow dynamic model' (S.D.M.), 'reservoir static model' (R.S.M.) and' reservoir dynamic model' (R.D.M.) were designed.

\section{Simultaneous flow static model (S.S.M.)}

In the simultaneous flow static model the two salt forming solutions, e.g., sodium phosphate and calcium acetate (for calcium phosphate) and the inhibitor (fruit juice), were taken in three separate burettes $(50 \mathrm{~mL})$ and were allowed to fall simultaneously into a $250 \mathrm{~mL}$ beaker with a slow (drop wise ) and equal speed. The whole operation took about $40 \mathrm{~min}$. at the end the mixture was digested in a hot water bath for $10 \mathrm{~min}$., cooled to room temperature and the precipitate was collected into a pre-weighed centrifuge tube by centrifuging small volumes at a time and rejecting the supernatant liquid. Next, the tube with the precipitate was dried in a hot air oven at $120^{\circ} \mathrm{C}$, cooled to room temperature and weighed till constant weight. Weight of the precipitate was determined.

\section{Simultaneous flow dynamic model (S.D.M)}

In the simultaneous flow dynamic model, the process was same except that the reaction mixture in the beaker was continuously stirred on a magnetic stirrer during the flow of salt forming solutions and the inhibitor.

\section{Reservoir static model (R.S.M)}

In this model, the whole amount of inhibitor solution $(50 \mathrm{~mL})$ was placed in the beaker in the beginning itself and the two salt forming solutions were allowed to run into it drop wise through burettes. Thus, a reservoir of inhibitor was created into which the salt forming burettes. Thus, a reservoir of inhibitor was created into which the salt forming solutions ran down. Rest of the operation was same as in the other models.

\section{Reservoir dynamic model (R.D.M)}

In the reservoir dynamic model the process was same as reservoir static model (R.S.M) except that the reaction mixture was stirred continuously on a magnetic stirrer during experiment. Simultaneous blank experiments with water in place of inhibitor were also carried out for evaluating the inhibition efficiency of inhibitors compared to water.

A blank experiment were carried out by mixing of salt forming solutions only without adding any inhibitors for evaluating the inhibitor efficiency of water compared to other inhibitors. All the experiments were conducted at room temperature. 
The salt forming solutions, sodium phosphate and calcium acetate (for calcium phosphate) and $0.01 \mathrm{M}$ solution of inhibitor (fruit juice) were taken in three separate burettes and the experiment was carried out in S.S.M. model. The experiment was repeated by using different concentrations of inhibitor (fruit juice). The same procedure was carried out in S.D.M model, R.S.M model, and R.D.M model by using the same fruit juice as inhibitor. The precipitate weights were recorded. The experiment was repeated for different salt forming solutions, e.g., sodium carbonate and calcium acetate (for calcium carbonate) and sodium oxalate and calcium acetate (for calcium oxalate).

\section{Results and Discussion}

The inhibition of mineralization of urinary stone forming minerals by fruit juice has been investigated in four different models. The effect of inhibitor efficiency was also studied in three different concentrations. Simultaneous blank experiments with water and without water were also carried out for evaluating the inhibition efficiency of inhibitor compared to water. All the experiments were conducted at room temperature.

Percentage efficiency of inhibitor was calculated using the following formula.

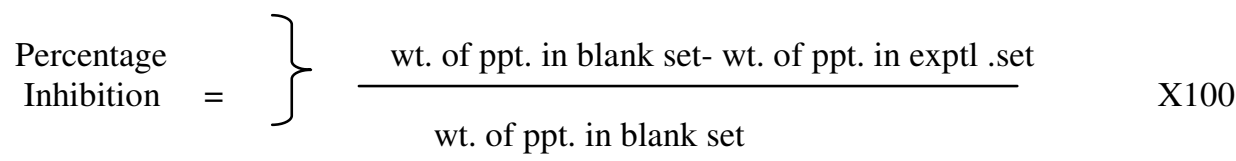

Inhibition efficiency of fruit juice towards the precipitation of calcium oxalate, calcium carbonate and calcium phosphate are recorded in Table 1-3. The efficiency of the juice has been shown by plotting a column chart (Figure 1-3).

Table 1. Inhibition of calcium oxalate mineralization by fruit juice Salt forming solution: $0.01 \mathrm{M}\left(\mathrm{CH}_{3} \mathrm{COO}\right)_{2} \mathrm{Ca}$ and $0.01 \mathrm{M} \mathrm{Na}_{2} \mathrm{C}_{2} \mathrm{O}_{4}$

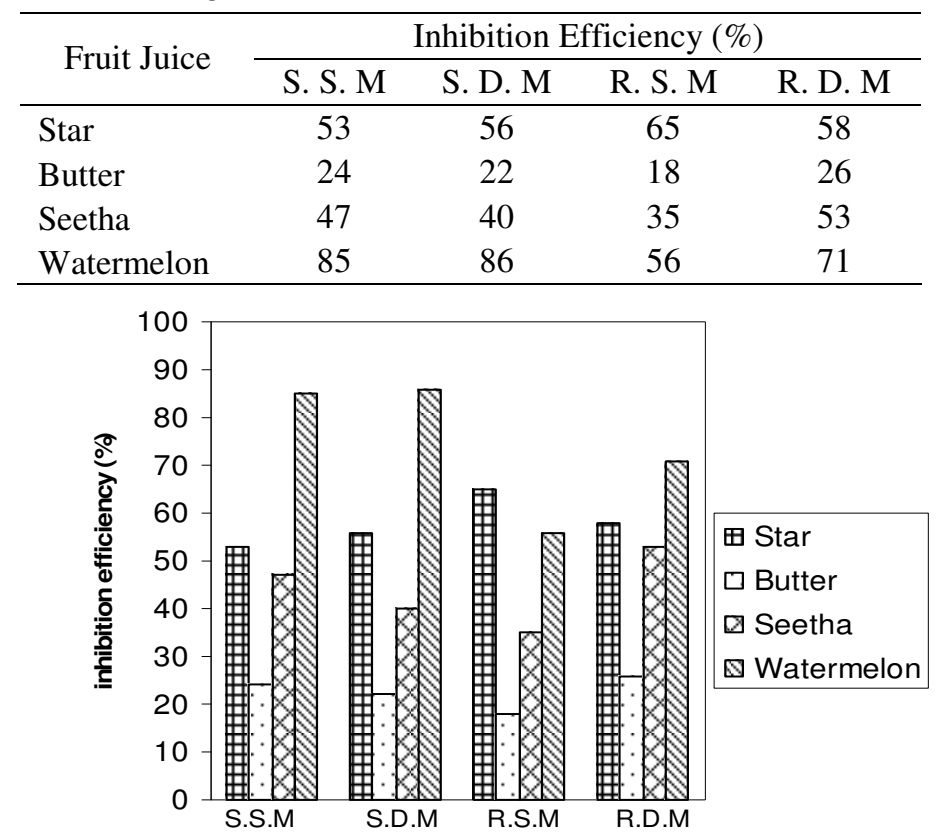

Figure 1. Inhibition of calcium oxalate mineralization by fruit juice. 
Table 2. Inhibition of calcium phosphate mineralization by fruit juice.

Salt forming solution: $0.01 \mathrm{M}\left(\mathrm{CH}_{3} \mathrm{COO}\right)_{2} \mathrm{Ca}$ and $0.01 \mathrm{M} \mathrm{Na}_{3} \mathrm{PO}_{4}$

\begin{tabular}{ccccc}
\hline \multirow{2}{*}{ Fruit Juice } & \multicolumn{4}{c}{ Inhibition Efficiency, \% } \\
\cline { 2 - 5 } & S.S.M & S.D.M & R.S.M & R.D.M \\
\hline Star & 42 & 38 & 47 & 46 \\
Butter & 23 & 21 & 17 & 27 \\
Seetha & 26 & 44 & 33 & 37 \\
Watermelon & 71 & 50 & 47 & 64 \\
\hline
\end{tabular}

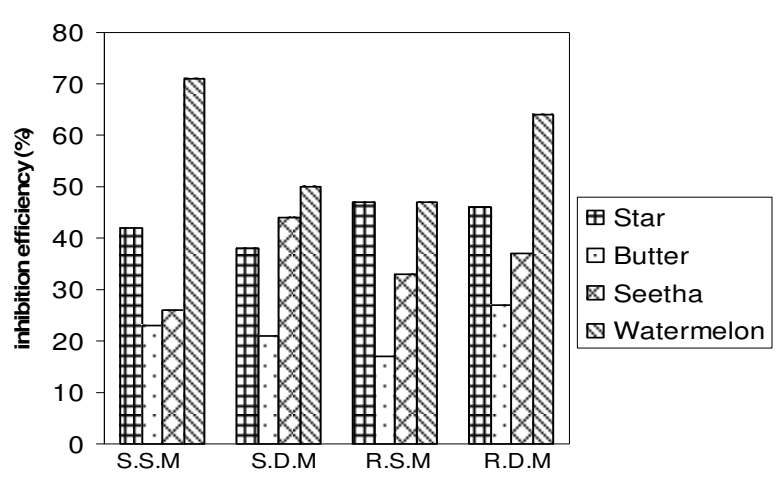

Figure 2. Inhibition of calcium phosphate mineralization by fruit juice.

Table 3. Inhibition of calcium carbonate mineralization by fruit juice.

Salt forming solution: $0.01 \mathrm{M}\left(\mathrm{CH}_{3} \mathrm{COO}\right)_{2} \mathrm{Ca}$ and $0.01 \mathrm{M} \mathrm{Na}_{2} \mathrm{CO}_{3}$

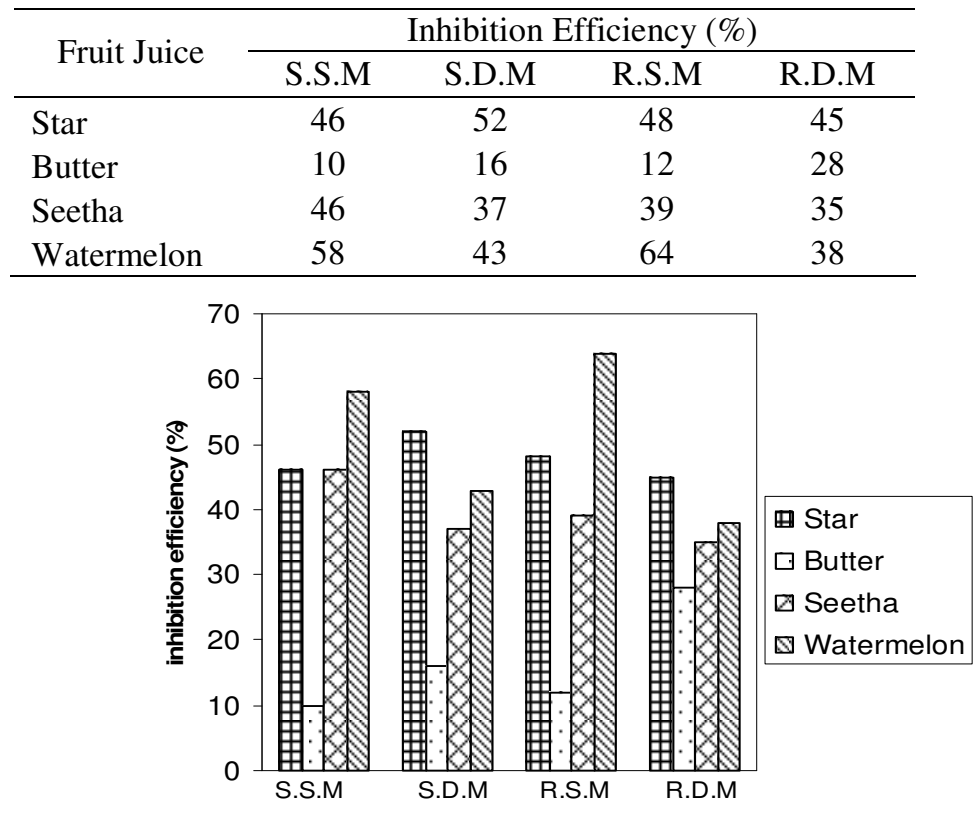

Figure 3. Inhibition of calcium carbonate mineralization by fruit juice. 
Study of the tables 1-3 and Figures 1-3 suggests that the watermelon is good inhibitor for mineralization of calcium phosphate, oxalate and carbonate. Particularly in case of phosphate the inhibition is very good on an average. In the case of carbonate, inhibition efficiency is less. The star fruit and seethe juice is a moderate inhibitor for all the minerals. On the other hand butter fruit juice shows poor inhibition for all the minerals. Thus it is seen that the inhibitory power of fruit juice is a function of their components. The active inhibiting components might be effective calcium chelating agents present in the fruits.

Instead of using fruit juice, the inhibition efficiency has been investigated by using water as inhibitor. It is observed that the water is also plays an significant role in preventing stone formation in the urinary tract. Ingestion of large amounts of fluids in the form of beverages such as tender coconut water, barley water, fruit juices and other soft drinks will help the patients to excrete over 2 liters of urine per day. Dilute urine prevents concentration of solids and the precipitation of crystals.

A comparative study of different models indicates that there is no significant difference is observed. All the fruits that we have presently studied are commonly edible ones. Their inhibition efficiency towards the mineralization of calcium phosphate, oxalate and carbonate suggests that the increased intake of these fruits would be helpful in urinary stone prophylaxis.

\section{References}

1 Agarwal, Text Book of Biochemistry, Goel Publishing House, Meerut.

$2 \quad$ James S and Elliot, J. Urol. $1973 \mathbf{8 2} 109$

$3 \quad$ Thind S K and Nath R Indian J. Med. Res. 1969571790

4 Kabra V, Chaturvedi R P, Gaur S V, Banerji B and Kabra S G Indian J. Surg. 19763833

5 Hadiya K R, Bhandari N S, Madhu B, Beniwal V K and Lakshminarayana J $J$. Human Ecol. 19991069

6 Anderson D A, Sriramachari S and Khandagle M K Indian J. Med. Sci. 196317632

7 Shorr E, Alamy T P, Solan M H, Taussky H and Toscani V Science 194296587

8 Rajagopal G, Venkatesan K, Ranganathan P and Ramakrishnan, Toxicol. Appl. Pharmacol. 197739543

$9 \quad$ Kumar S and Jethi R K Indian J. Med. Res. 1975631667

10 Rao T V R K and Sofia Bano Asian J. Chem., 200012467 


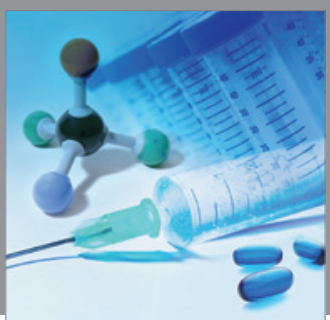

International Journal of

Medicinal Chemistry

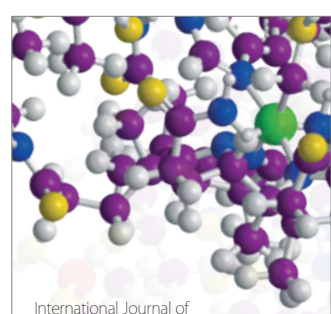

Carbohydrate Chemistry

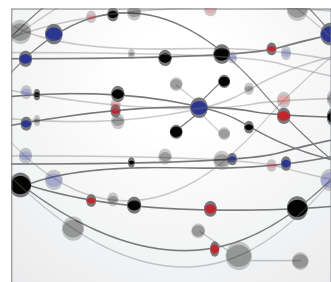

The Scientific World Journal
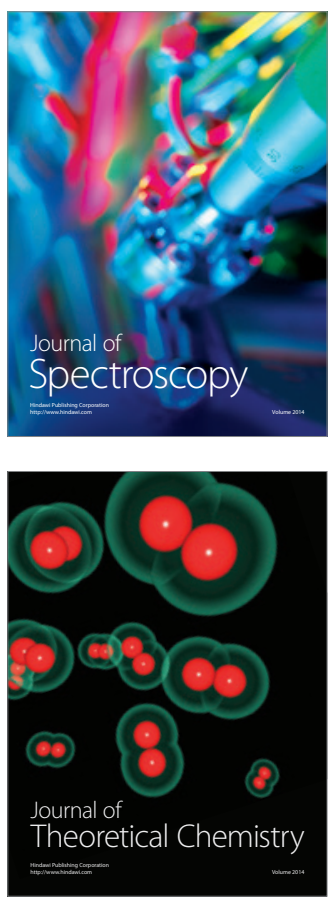
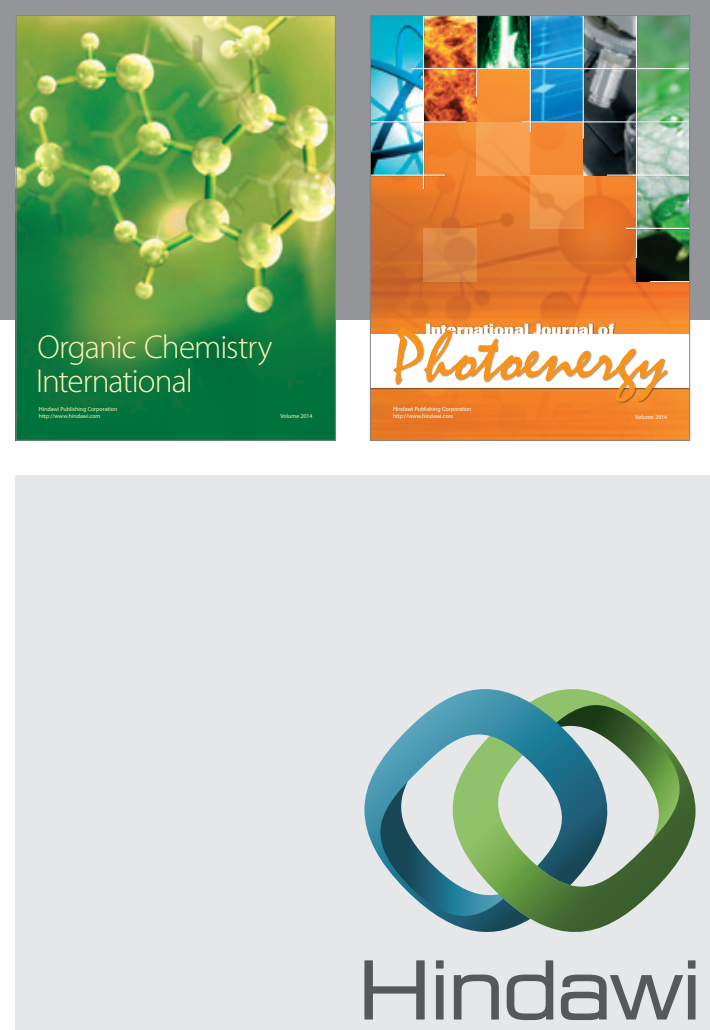

Submit your manuscripts at

http://www.hindawi.com
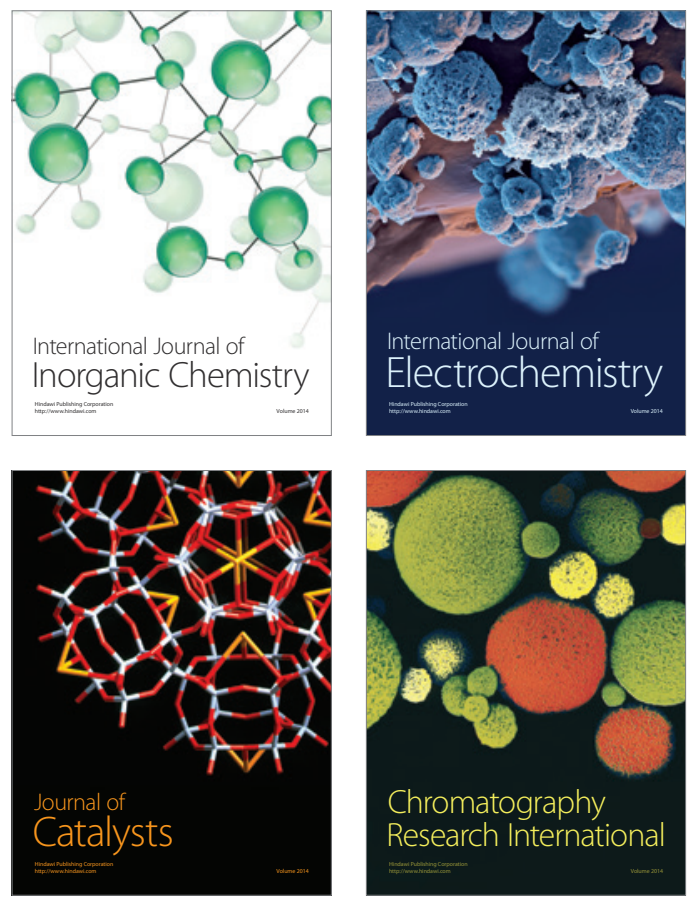
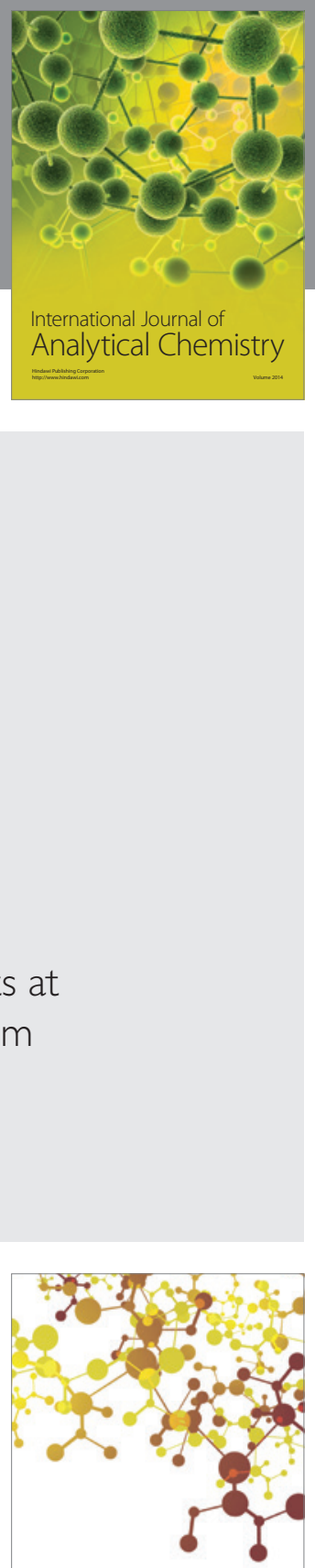

Journal of

Applied Chemistry
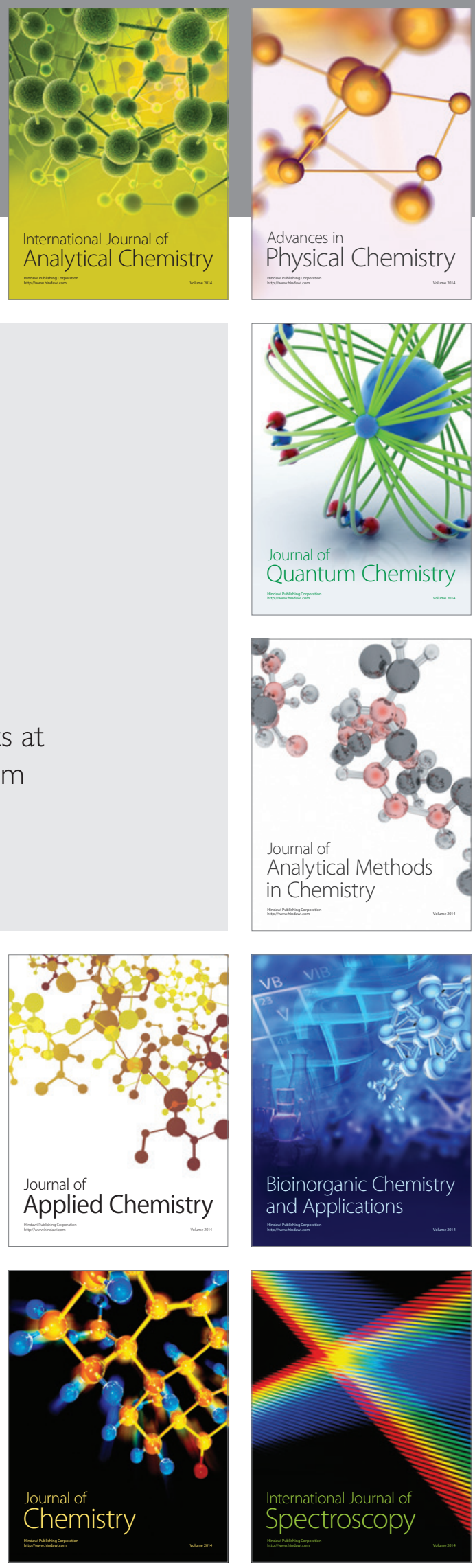